\section{EFFECTS OF ADAPTIVE CONTROL OF THE DRILLING PROCESS}

KAROL VASILKO

Technical University of Kosice, Faculty of Manufacturing Technologies with seat in Presov, Presov, Slovakia

DOI: 10.17973/MMSJ.2020_11_2020040

karol.vasilko@tuke.sk

The paper analyses the drilling as the machining process with applied adaptive control. Experience with the use of NC machine tools shows that cutting conditions cannot be optimized without more detailed knowledge of the machining process. The numerical control of the machine tool gives more space to the technologist for creative control of the cutting process. The essence of the adaptive machining system lies in the response to the machining conditions (change in allowance, cutting width, material hardness). In doing so, it maintains a constant selected parameter, e.g. cutting force. In finishing operations, such a criterion may be the quality of the machined surface.

KEYWORDS

Machining, Drilling, Machining Time, Cutting force, Durability

\section{INTRODUCTION}

The method of adaptive control for the dynamical systems can be numerically simulated to find an effectively approach. Thus it can be applied to numerous engineering problems, for example, stabilization of off-road vehicles subjected to sudden unevenness of the surface, stabilization of air-plane wings under turbulences, masts under strong wind blows, or high buildings subjected to seismic excitation, or satellite antennas impacted by meteorites. [Wasilewski 2019].

The application of adaptive control of machining on CNC machines enables new options for process optimisation. The increase of tool durability and shortening machine time is the result. The operator is required to know the machining process, mainly the importance of tool geometry and the influence of cutting conditions on the result of machining. An important effect can be seen in processes during which there occurs a change of some geometry parameter, i.e. machining width or cross-section cut-off layer.

Classical production machining methods are based on cutting conditions: cutting speed $v_{\mathrm{c}}$, depth of cut $a_{\mathrm{p}}$, feed $f$. These are usually kept constant during the entire machining process of a certain workpiece surface [Hammer 1983, Kalpakjian 2001]. The change in cutting speed occurs for example when turning the workpiece end face at a constant spindle speed. The depth of cut varies when machining forgings and castings that have technological bevels [Hammer 1983]. The feed rate does not normally change during machining, as this ensures a constant quality of the machined surface [Vasilko 2019]. The stability of the cutting conditions determines the machine time $T$ for which the general relation formula:

$T=\frac{l}{n . f}[\mathrm{~min}]$

where $I$ is the length of the surface to be machined; $n$ is the rotational frequency of the workpiece (or tool); $f$ is the feed rate per one revolution of the workpiece (or tool) [Kalpakjian
2001]. A deeper analysis of the machining process shows that a purposeful change in cutting conditions $(n, f)$ can positively affect the cutting process and its results. Moreover, it is shown that implementation of control ensures the required vibratory operation mode (to ensure chip segmentation, the drill bit oscillates in axial direction) in a wide range of cutting conditions [Ivanov 2018].

\section{CONTROL OF DRILLING PROCESS}

Cutting speed and geometric parameters are being changed for classical helical drills along the cutting edge according to Fig. 1. Besides this, the existence of cross-cutting edge makes it harder for the drill to cut in from its first touch with the workpiece up to the contact along all length of the cutting edges.

Mainly face angle changes considerably, on which the chipcreating process depends. Similar unfavourable conditions occur when the drill exits the hole and often leads to priority damage of the drills.

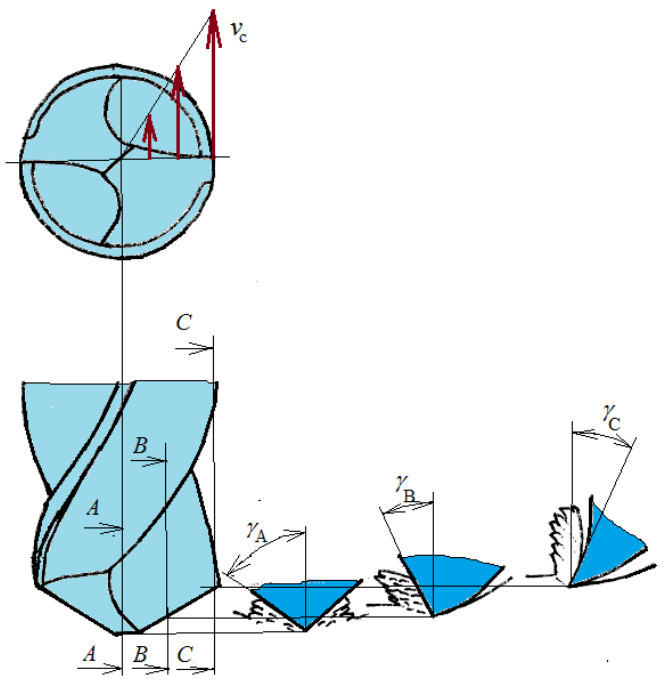

Figure 1. Change of geometric parameters of the drill when cutting into the workpiece

In Fig. 2 there is the result of the experiments aimed at the measurement of axial cutting force (more in [Murcinkova 2013]) when drilling steel and cast iron with the drills made of the high-speed steel.
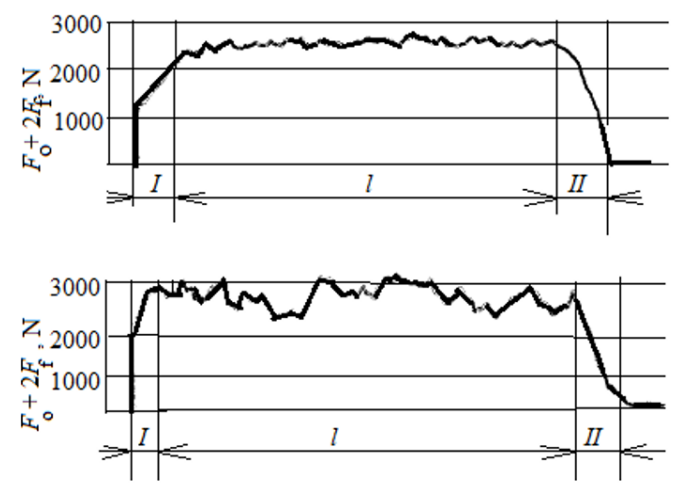

Figure 2. Change of axial forces during drilling the holes in cast iron (a) and steel (b) with drills made of high-speed steel HS12-1-2, diameter $12 \mathrm{~mm}$. Cutting conditions: (a) $\mathrm{f}=0.21 \mathrm{~mm}, v_{c}=23.7 \mathrm{~m} \cdot \mathrm{mint}^{-}$) , (b) $f=0.16 \mathrm{~mm}, v_{\mathrm{c}}=23.7 \mathrm{~m} \cdot \mathrm{min}^{-1}$

It can be seen that when the drill enters the engagement, an axial cutting force $\left(F_{\mathrm{o}}+2 F_{f}\right)$ grows. It is conditioned by the fact 
that at the first touch, only the chisel edge is in engagement. The face angle is negative, which causes considerable plastic deformation of cut material when it is being transformed into the chip (more in [Murcinkova 2016]). The engagement gradually widens to both cutting edges and by this, the force $F_{f}$ grows. The character of the growth of axial cutting force depends on the stiffness of the technological system [Voronov 2007]. The higher the stiffness, the steeper the growth of the axial force. The zone of continuous drilling of steel shows in observable force variation, which is the effect of the creation of the chip characteristic for steel (continuous chip with yields which affect whole chip cross-section). Higher cutting force dynamics can be seen in cast iron drilling because there occurs a fissure-creation process together with the creation of a segmented chip. Similarly, when the drill leaves the engagement, the decrease of the cutting force is different for the cast iron and for the steel. The more fluent decrease has been recorded when cast iron has been drilled, which is probably the effect of the gradual recovery of the elastically deformed system. For steel, that decrease is steeper.

Experimental tests have proved that the character of the cutting force change when entering and exiting the engagement can be influenced by the change of revolution frequency of the drill and the change of the feed which can be ensured by the correction of the control program of the NC machine.

The durability of drills used in regular cutting conditions and changing feed has been compared experimentally. The tests have been conducted when drilling the cast iron with crust by the tools made of high-speed steel HS12-1-2 of diameter 12 $\mathrm{mm}$ and length $40 \mathrm{~mm}$. Standard cutting conditions recommend the use of feed $f=0.21 \mathrm{~mm}$. For ther modified regime, the feed rates decreased by $40-50 \%$ with the drill cutting in and exiting. At the same time, the feed rates have been increased by $20-25 \%$ when drilling in the central part of the hole. Respective feed rates have been: $f_{1, \| l \mid}=0.18 \mathrm{~mm}, f_{\| 1}=$ $0.25 \mathrm{~mm}$. This process can be reasoned by the fact that during regular drilling a slightly smaller feed than the allowed one is selected due to complex feed conditions when the drill comes into the engagement.

In Fig. 3 there is technological cycle of drilling in regular and modified regime.

a)

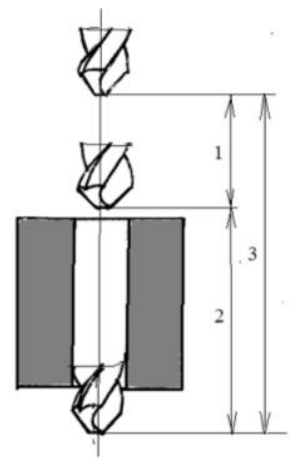

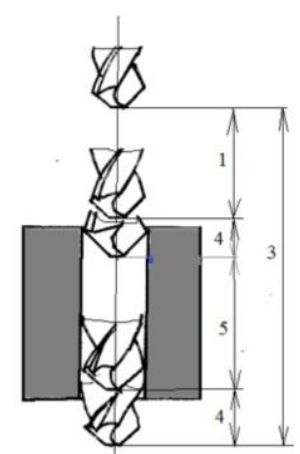

Figure 3. Technological process of drilling, (a) standard, (b) modified, 1 - quick feed, 2 - operational feed, 3 - reverse quick feed, 4 decreased feed, 5 - increased feed

In Fig. 4, a comparison of average durability of drill series when drilling in standard and modified conditions is shown.

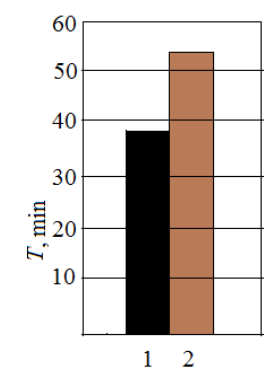

Figure 4. Tool durability during drilling at standard conditions (1) and variable feed (2)

It can be seen that tool durability has grown considerably when drilling holes with variable feed. At the same time, machine time has decreased by approximately $10 \%$.

The following tests have been oriented to the study of the influence of cutting speed on drills durability. The tests have been performed when drilling holes in cupboard parts made of grey cast iron with crust on the side where the drills have exited the engagement. Classical helical drills with diameter $17.5 \mathrm{~mm}$ made of high-speed cutting steels HS7-4-2-5 and HS12-1-2 and sintered carbide K10, respectively, have been used as tools. Holes with a length of $50 \mathrm{~mm}$ have been machined. Fluent change of spindle revolutions frequency helped in obtaining different cutting speeds at continuous drilling and exiting the engagement. At standard machining, cutting speeds selected from standards, $16.5 \mathrm{~m} \cdot \mathrm{min}^{-1}$ for the drills made of high-speed cutting steels, and $26 \mathrm{~m} \cdot \mathrm{min}^{-1}$ for the drills made of sintered carbide have been selected.

When exiting the engagement, cutting speed has been decreased by $25 \%$, i.e. to $12.5 \mathrm{~m} \cdot \mathrm{min}^{-1}$ for high-speed drills and $21 \mathrm{~m} . \mathrm{min}^{-1}$ for drills made of sintered carbide, respectively. The feed has been constant, 0.32 , and $0.28 \mathrm{~mm}$, respectively. The technological process of drilling in both cases is shown in Fig. 5 . The results after statistic processing are shown in Fig. 6 . a)

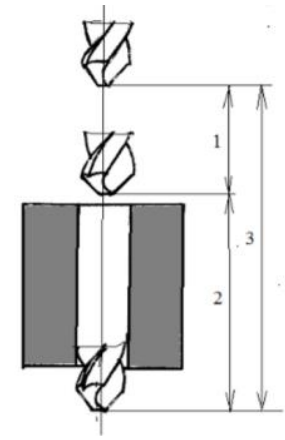

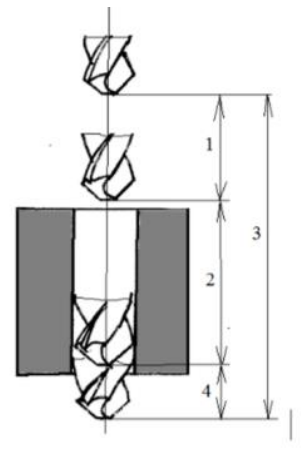

b) b)

Figure 5. Technological process of drilling, (a) standard, (b) modified, 1 - quick feed, 2 - standard feed, 3 - reverse quick feed, 4 - decreased feed

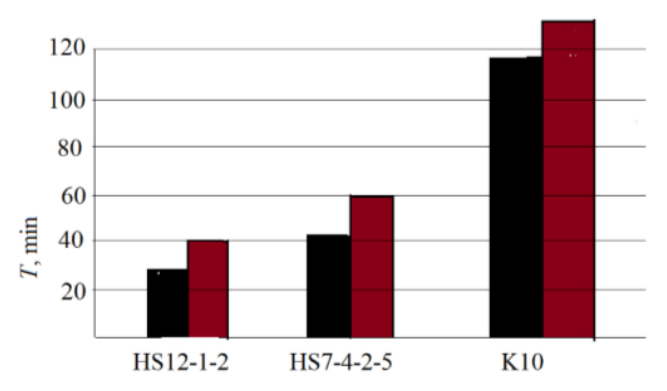

Figure 6. Average drill durability at drilling with standard regimes (left columns) and with variable cutting speed 
Another test series has been devoted to the conditions of continuous cutting into drilled material. The zone of cutting has been divided into several sections along which cutting speed has been varied. The tests have been performed with drills with $12 \mathrm{~mm}$ diameter which corresponds to the trajectory of cutting of length $4.8 \mathrm{~mm}$. This section has been divided into three parts of $1.5 \mathrm{~mm}$ each. In each part, different cutting speeds and feeds have been selected on the basis of the analysis of the machining scheme.

When cutting in (the first part with more difficult conditions) when the chisel edge deforms the material, the feed has been changed twice and the spindle revolutions frequency has increased four times. Analogically, in the second part, the feed has decreased by $20-25 \%$, with a corresponding increase of spindle revolutions frequency it has been 1.5 times. Cutting conditions in the third part have corresponded with the standard ones. The results of the axial force measurement are shown in Fig. 7.

a)

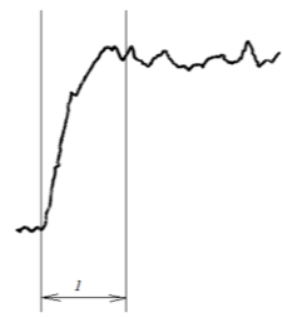

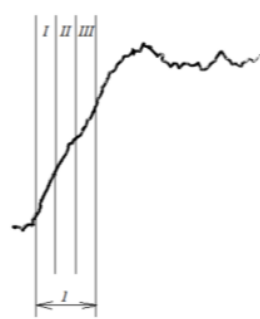

Fig. 7. Character of change of axial force when the drills made of HS12-1-2 and steel C45 cut in the workpiece. (a) standard regime, (b) after division of the zone of cutting in into three sections, (a) $f=0.14$ $\mathrm{mm}, n=800 \mathrm{~min}^{-1}\left(v_{\mathrm{c}}=30 \mathrm{~m} \cdot \mathrm{min}^{-1}\right)$, (b) $I-D_{1}=4 \mathrm{~mm}, n=2400 \mathrm{~min}^{-1}$ $\left(v_{\mathrm{c}}=30 \mathrm{~m} \cdot \mathrm{min}^{-1}\right), I I-D=8 \mathrm{~mm}, n=1200 \mathrm{~mm}^{-1},\left(v_{\mathrm{c}}=30 \mathrm{~m} \cdot \mathrm{min}^{-1}\right), I I I-$ $D=12 \mathrm{~mm}, n=800 \mathrm{~min}^{-1}\left(v_{\mathrm{c}}=30 \mathrm{~m} \cdot \mathrm{min}^{-1}\right)$.

It can be seen that at the change of frequency of spindle revolutions and feed, a more fluent course of cutting force can be obtained, at the same time there occurs shortening of machine time $30-35 \%$.

A fluent change of spindle revolutions frequency presents a more effective method to improve the conditions of cutting in. Recent CNC systems enable to change the frequency of spindle revolutions and feed fluently, according to corresponding law and at different machining system. The results of studies have shown that the change of feed and cutting speed when the drill enters and exits the feed can considerably improve the character of transit processes in this area. Another positive result of experimental tests is the fact that besides the improvement of drill working conditions in transit section, also the probability of breaking off the drill decreases.

\section{OPTIMISATION OF CUTTING CONDITIONS DURING DRILLING IN THE CENTRAL PART OF HOLE}

In the previous part, the paper has dealt with the optimisation of cutting conditions in drill transit conditions. Next, it will deal with the optimisation of the process of drilling.

The first part of the experiments has been performed only at the regulation of the feed. The range of regulation allowed by the system of adaptive control has been $20-120 \%$ with the step $10 \%$. It means that standard feed is considered to be $100 \%$, feed in the course of regulation can be decreased by $80 \%$ and increased by $20 \%$.
In Fig. 8 there are results of measurement of the character of axial force character during drilling of the basic part of the opening at standard conditions of drilling and with the use of the system of adaptive control at different feed rates.

The comparison of the courses of $a$ and $b$ has shown that in comparison with the standard regime it is impossible to obtain a smaller variation of cutting force when using adaptive control with the range of regulation $20-120 \%$ and required performance $0.7 \mathrm{~kW}$. Machine time increases by $20 \%$. It can be explained by the fact that when drilling steel, a continuous chip is created and when it breaks off, the axial force decreases. When drilling with adaptive control, the system reacts to the change of this force, and at the regulation by the influence of inertia, mainly at a large range of regulation it evokes even higher fluctuation of the force. With the decrease of the range of regulation (Fig. $8 \mathrm{c}, \mathrm{d}, \mathrm{e}$ ), the dynamic element of cutting force decreases gradually, and in the range of regulation by 100 $-120 \%$ it is considerably smaller compared with work without regulation. At the same time machine time is shortened by about $10 \%$.

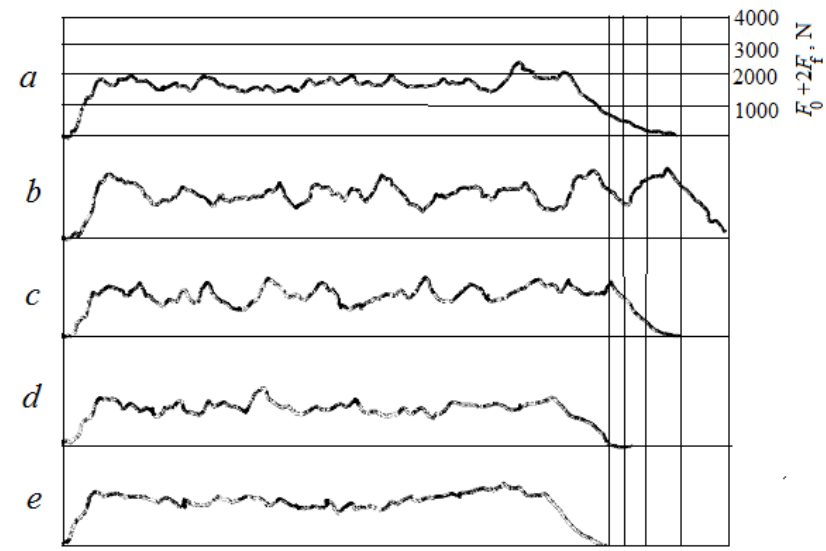

Figure 8. Character of change of axial force in different range of regulated feed when drilling steel C45 with drills z HS12-1-2, diameter $12 \mathrm{~mm}, v_{\mathrm{c}}=30 \mathrm{~m} \cdot \mathrm{min}^{-1}$, hole length: $40 \mathrm{~mm}$. (a) at standard cutting conditions: $f_{\mathrm{m}}=114 \mathrm{~mm} \cdot \mathrm{min}^{-1}, N=0.7 \mathrm{~kW}$, (b) at the range of regulated feed $20-120 \%, f_{m}=22-137 \mathrm{~mm} \cdot \mathrm{min}^{-1}$, (c) $40-120 \%$ (114 $-136 \mathrm{~mm} \cdot \mathrm{min}^{-1}$ ), (d) $60-120 \%$, (e) $80-120 \%$.

\section{OTHER APPLICATIONS}

A significant effect of adaptive control can be achieved during milling.
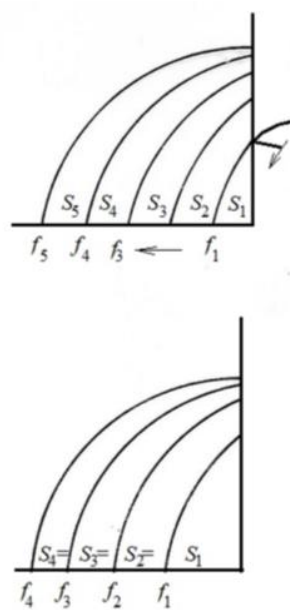

b)

Fig. 9 Schema of workpiece milling by constant (a) and adaptively controlled feed (b). 
In Fig. 9 is a schema of the gradual entry of the teeth of the cutter from the corner of the workpiece into full engagement. With a constant feed $f$, Fig. 9a, there is a significant increase in the instantaneous cross-sectional area of the cut and thus increase of the cutting force. By adjusting the milling parameters, it is possible to achieve that the cutting force will be the same with each cut, Fig. $9 \mathrm{~b}$.

In addition, there are cases that require controlling the depth of cut $a_{\mathrm{p}}$. A typical example is thread turning, which takes place in several cutting tool cuts. In Fig. 10, the machining schema with the same depth of cut for each engagement and a gradually decreasing depth of cut are shown. In both cases, the last cut can be "finished" with a small depth of cut.

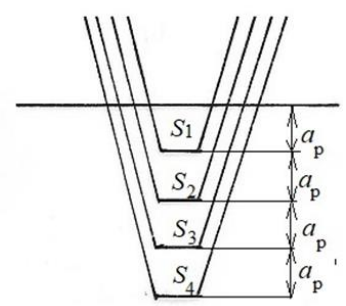

a)

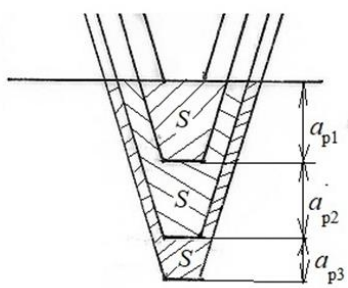

b)

Fig. 10 Schema of gradual thread turning with the same (a) and decreasing tool feed (b)

\section{CONCLUSIONS}

The study of adaptive control application to the drilling process is presented. Moreover, its applications to milling and thread turning are shown. The emphasis should be given to the phenomena of the cutting process when designing and implementing adaptive control.

The smooth (not sudden) change of cutting force results in slowly, not intensive, tool wear, and thus the tool life is longer. To set the conditions of adaptive control, the critical analysis of cutting forces, feed, and cutting speed when machining the feature (e.g. drilling the hole) have to be made whereas the large and sudden change of cutting force values is harmful to a cutting tool (e.g. drill). The starting point for designing the adaptive control is an analysis of the standard process, mainly the relationship of the cutting conditions and the cutting forces.

In the presented case of the drilling process, the change of spindle revolutions and feed causing a more fluent course of cutting force. It results in increasing the tool life up to $40 \%$ (Fig. 4) and even the shortening of machine time $30-35 \%$ (Fig. 7) which are significant improvements.

\section{ACKNOWLEDGMENTS}

This work was supported by the Slovak Research and Development Agency under Contract No. APVV-18-0316.

\section{REFERENCES}

[Hammer 1983] Hammer, H. Verbesserung der Wirtschaftlichkeit durch flexible Automatisierung beim Bohren und Fräsen. ZwF Zeitschrift für wirtschaftliche Fertigung, 1983, Vol.78, No.2, pp.77-86. ISSN 0044-3743

[Ivanov 2018] Ivanov, I.I. and Voronov, S.A. Processing parameters influence on dynamics of vibratory drilling with adaptive control. In: MATEC Web of Conferences Vol. 226, p. 02001. EDP Sciences, 2018.

[Kalpakjian 2001] Kalpakjian, S. Manufacturing Engineering and Technology. Pearson Education India; 2001.

[Murcinkova 2013] Murcinkova, Z. and Krenicky, T: Implementation of virtual instrumentation for multiparametric technical system monitoring. In: SGEM 13th International Multidisciplinary Scientific Geoconference: Informatics, geoinformatics and remote sensing, Albena, Bulgaria, STEF92 Technology Ltd, pp. 139-144, 2013.

[Murcinkova 2016] Murcinkova, Z. and Vasilko, K.: Thermophysical aspects of chip machining. High Temperatures-High Pressures, 2016, Vol.45, No.4.

[Vasilko 2019] Vasilko, K., Murcinkova, Z. and Nosal, J. Materials and machining trends in terms of the existing axioms of the machining theory. Materialwissenschaft und Werkstofftechnik 2019, Vol.50, No.2, pp.165-173.

[Voronov 2007] Voronov, S.A., Gouskov, A.M., Kvashnin, A.S., Butcher, E.A. and Sinha, S.C.: Influence of torsional motion on the axial vibrations of a drilling tool. Journal of Computational and Nonlinear Dynamics, January 2007, Vol.2, No.1, pp.58-64. [Wasilewski 2019] Wasilewski, M., Pisarski, D., Konowrocki, R. and Bajer, C.I. A new efficient adaptive control of torsional vibrations induced by switched nonlinear disturbances. International Journal of Applied Mathematics and Computer Science. June 2019, Vol.29, No.2, pp.285-303.

\section{CONTACTS}

Dr.h.c. prof. Ing. Karol Vasilko, DrSc.

Technical University of Košice,

Faculty of Manufacturing Technologies with seat in Prešov,

Department of Automobile and Manufacturing Technologies,

Bayerova 1, 08001 Prešov, Slovakia

karol.vasilko@tuke.sk 